\title{
Sonic injection in sulphide bath smelting: an update
}

\author{
by J.P.T. Kapusta*
}

\section{Synopsis}

The copper smelting industry faces increasingly stringent environmental regulations and must continue driving innovation to reduce energy usage in its production chain. With the coming of age of 'bottom-blowing' copper technologies in China over the last decade, much renewed attention has been brought to tuyere bath smelting for clean copper-making. Since bottom-blowing sonic injection was originally developed and implemented in steelmaking in the 1970s and lead smelting in the 1990s, the time seems appropriate to revisit the sonic injection concepts and dispel some myths. After reviewing the trends in the copper industry and providing a brief historical context of research and development related to sonic injection, the author presents a comparison of the main submerged tuyere bath smelting technologies, namely the Noranda Reactor (NR), the Teniente Converter (TC), and the Chinese Bottom-Blowing Smelting Furnace (SKS/BBS) for copper, and the Queneau-Schuhmann-Lurgi Reactor (QSL) for lead. The core of this article, however, consists of a brief description of the fundamental theories for sonic injection (jetting regime) and 'sonic flow mapping' to illustrate the relationship between the minimum tuyere back-pressure required to achieve sonic flow and the tuyere internal diameter. The article also offers a comparison between side- and bottom-blowing in jetting regime before concluding with the author's vision of the new trend in submerged tuyere bath smelting.

Keywords sulphide smelting, bottom blowing, sonic injection.

\section{Introduction}

In the last decade, developments in the copper smelting industry have been driven by two key concepts: (1) increasing cleaner smelting capacity to meet the world's growing copper demand, as illustrated in Figure 1, and (2) increasing process off-gas capture to comply with more stringent environmental regulations and abide by a corporate social responsibility ethic of a clean work environment (for smelter employees) and clean air (for families living around smelters). The copper smelting industry has also faced some major challenges in the last few decades, including (1) low treatment and refining charges (TC/RC or processing fees) impacting custom smelters, (2) lower concentrate quality and grades with higher levels of impurities (e.g. As and $\mathrm{Hg}$ ), (3) higher processing and transportation costs due to the rising cost of energy, (4) restrictions in process intensification (tonnage oxygen usage) due to furnace integrity limits, and (5) scarcity of educated and trained personnel due to fewer metallurgists graduating from pyrometallurgical school programmes combined with a high retirement rate of skilled workers.

In a nutshell, the challenge is tantamount to producing more with lower-quality concentrates and less-skilled workers while lowering the smelter environmental footprint by reducing the energy usage and increasing off-gas capture at times when profit margins are low (set by fluctuating TC/RC). The obvious approach would be to increase smelting intensity with higher oxygen usage to produce more copper while reducing process off-gas generation, 'removing the dead-hands of nitrogen' as per the famous words of Paul Queneau Sr. (1977), and therefore reducing the off-gas treatment costs and lowering the smelter's fugitive emissions. This 'obvious' approach has been in the minds of smelter men and women ever since tonnage oxygen became available at an affordable price. A testimony to this fact is the development of oxygen bath and flash smelting to replace lowintensity processes, such as the reverberatory furnace, as far back as the 1950s.

The more recent trend in copper processing in the last two or three decades has been for copper smelters to select flash smelting and/or converting or top-submerged lancing (TSL) technologies, rather than the bath smelting furnaces of the 1970s such as the Noranda Reactor and Teniente Converter. For the 2003 copper smelter survey, 53 smelters responded to the questionnaire, representing about $73 \%$ of the 2003 world copper smelter production of 12.4 Mt (Kapusta, 2004). Notably, the survey showed that flash smelting reigned supreme at the time, accounting for $48.7 \%$ of the copper

* BBA Inc., Canada.

(C) The Southern African Institute of Mining and Metallurgy, 2018. ISSN 2225-6253. This paper was first presented at the Copper Cobalt Africa, incorporating the 9th Southern African Base Metals Conference, 9-12 July 2018, Avani Victoria Falls Resort, Livingstone, Zambia. 


\section{Sonic injection in sulphide bath smelting: an update}

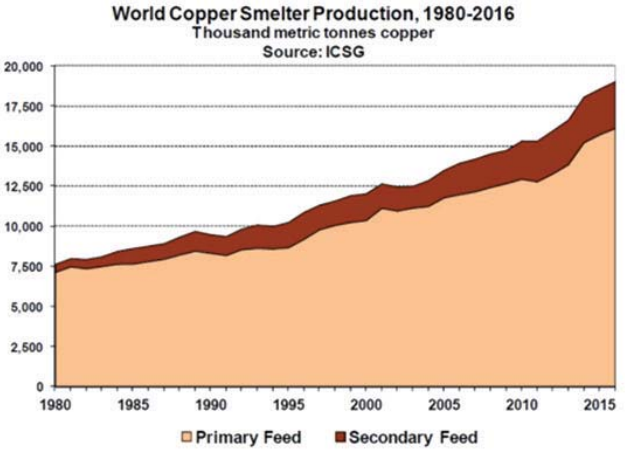

(a)

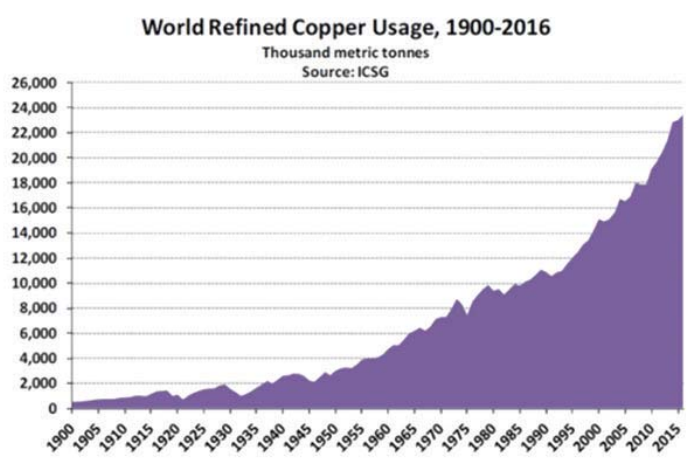

(b)

Figure 1-(a) World copper smelter production from 1980 to 2016, and (b) world refined copper usage from 1900 to 2016 (International Copper Study Group, 2017)

produced by the respondents, while all bath smelting technologies combined represented $36.7 \%$ of that same copper production. Bath smelting with side-blowing submerged tuyeres represented a mere $20 \%$.

Fifteen years have passed since the 2003 survey and the trend seems to have been shifted by the Chinese towards what they call 'modern bath smelting technology' as a dozen or more smelters in China have been built using their socalled 'bottom-blowing smelting' furnaces. Not only have the Chinese repositioned copper bath smelting with horizontal cylindrical vessels, but they have also positioned their process in the lower quartiles of the cash cost curves published by various institutions. Their ability to do so stems from the adoption of ultra-high oxygen-shrouded injectors in the reactors, transforming them into high-intensity smelting units. My goal is to provide readers with a few pointers to understand how this was accomplished against all odds.

\section{Historical context}

Mackey and Brimacombe (1992) reported that Guy Savard and Robert Lee of Canadian Liquid Air transformed the metallurgical landscape in 1966 with their invention of the high-oxygen-shrouded injector, commonly known as the Savard-Lee tuyere (Savard and Lee, 1966). That invention became the enabling oxygen injection technology for the advent of the oxygen bottom-blowing metallurgy - or OBM process - which revolutionized the steel industry in the 1970s.

If Savard and Lee were the first, over a 20 -year period in the 1950s and 1960s, to test and develop sonic injection technologies and then implement their concentric tuyere in steelmaking, I consider that Noranda, at its research centre in Montreal, pioneered the fundamental research to understand the dynamics of submerged gas injection in nonferrous pyrometallurgy (Themelis, Tarassoff, and Szekely, 1969). The true breakthrough, however, came from the Brimacombe research group at the University of British Columbia, which identified and characterized for the first time two distinct injection regimes: bubbling and jetting (Oryall and Brimacombe, 1976; Hoefele and Brimacombe, 1979), as illustrated in Figure 2.

Following the pioneering work of Savard and Lee, Noranda, and the University of British Columbia, much attention and research around the world were devoted to the dynamics of submerged gas injection into molten metals. A wealth of knowledge on gas injection phenomena was produced in the golden decades of the 1970s and 1980s when gas injection dynamics research, both in the laboratory and during plant trials, was conducted to elucidate the critical aspects of submerged gas injection, including the characterization of steady jetting conditions or the quantification of gas penetration into molten baths. This broad know-how, in large part generated in Canada, has served as the basis for my own understanding of gas injection phenomena and for the development of sonic injection technologies. Although I have previously published a detailed review of the development of the Savard-Lee tuyere and its subsequent adoption and adaptation to nonferrous smelting and converting (Kapusta, 2013; Kapusta and Lee, 2013), I will use this article to further share some of my insights into sonic injection.

\section{Submerged tuyere bath smelting technologies}

For the sake of brevity, I will discuss, in this paper, only the copper bath smelting technologies using horizontal cylindrical vessels; namely, the Noranda Reactor (NR), the Teniente Converter (TC), the Queneau-Schuhmann-Lurgi Reactor

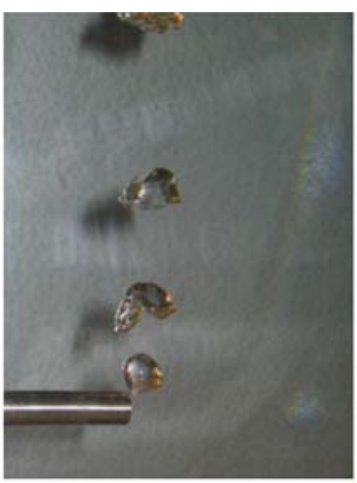

(a)

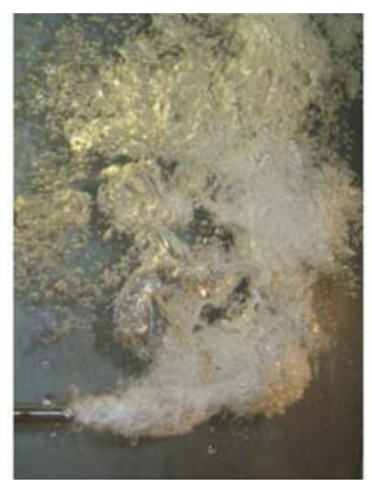

(b)
Figure 2-Still images of compressed air continuously injected into water: (a) bubbling regime with discrete gas bubbles and (b) jetting regime with fully developed gas jet (Joël P.T. Kapusta Archives) 


\section{Sonic injection in sulphide bath smelting: an update}

(QSL), and the Bottom-Blowing Smelting Furnace (SKS/BBS). A similar analysis would also be valid for the bath converting vessels (Peirce-Smith, Hoboken, and bottom-blowing converters). The NR and TC use conventional side-blowing low-pressure tuyeres while the QSL and SKS/BBS use bottom-blowing high-oxygen-shrouded injectors. The NR and TC are known to operate in bubbling regime and the QSL in jetting regime, but the actual mode of operation of the SKS/BBS, bubbling or jetting regime, is still unclear. In this section, I will attempt to shed some light by providing a brief gas dynamics analysis and some explanations about the differences between conventional low-pressure and sonic injection.

\section{The Noranda Reactor and Teniente Converter}

In a short course on gas injection phenomena that I have been offering for over 15 years, and presented in part at a conference (Kapusta and Richards, 2009), I review the dynamics of submerged gas injection and illustrate the concepts with images and videos from laboratory research and plant trials. One key conclusion is that conventional lowpressure, single-pipe tuyere injection is characterized by four main phenomena.

> Although injected continuously, the gas discharges as large discrete bubbles in the molten bath - hence the term bubbling regime - with a frequency of 8 to 12 bubbles per second and a bubble diameter in the range of 40 to $70 \mathrm{~cm}$.

> The large discrete bubbles do not penetrate forward into the molten bath but rise vertically above the tuyere tip, causing the oxidation reactions to occur at the refractory wall and resulting in severe tuyere-line damage.

> The collapsing of large bubbles at the bath surface generates bath slopping and splashing conditions, resulting in accretion formation on the converter mouth, production downtime to clean the mouth, and increased damage to the refractory bricks around the mouth.

> After each bubble detachment, i.e., 8 to 12 times per second, molten metal penetrates and solidifies inside the tuyeres, forming a plug that hinders the flow of gas and requires mechanical punching to be dislodged, further increasing tuyere-line damage.

In addition to tuyere blockage, gas flow rate fluctuations, tuyere punching, and refractory damage, conventional tuyere injection under bubbling regime is also characterized by a lower vessel intensity due to limited oxygen enrichment levels and to gas leaks and losses of up to $15 \%$ through the tuyere body during punching, as well as an increased predisposition to fugitive emissions due to higher off-gas volumes at lower $\mathrm{SO}_{2}$ strength. In fact, all bath smelting, converting, and refining vessels using side-blowing, including the NR and TC, Peirce-Smith and Hoboken converters, and anode furnaces, were developed for and still operate under low-pressure bubbling conditions with all the limitations and hindrances listed above. Over time, rather than addressing the cause of the problems - the unfavourable gas dynamics of the bubbling regime - the nonferrous industry focused instead on mitigating the consequences with new technological developments. Great examples of such mitigating technologies were the invention of the automatic punching machines to reopen the blocked tuyeres and the development and implementation of secondary and tertiary hoods to capture the large off-gas volumes and associated fugitive emissions produced under low-intensity bubbling regime.

A step back in history will show that when the NR and TC were developed in the 1970s, the quality of copper concentrates was high (35-40\% Cu), which imposed some constraints in processing, even at a time when tonnage oxygen was becoming more affordable and common in copper smelters. In their paper on new and emerging technologies in sulphide smelting, Mackey and Tarassoff (1983) provided the elements to understand how copper smelters in the early 1980 s were evolving to improve their energy footprint while increasing throughput. With one diagram, reproduced in Figure 3, Mackey and Tarassoff illustrated the fundamental concept that autogenous smelting of a chalcopyrite concentrate in a flash or bath smelting furnace had an upper limit of oxygen enrichment. This limit, when producing a $75 \%$ matte grade, was about $48-50 \% \mathrm{O}_{2}$ for a wet concentrate ( $7 \%$ moisture), as marked on the figure by the blue arrow added to the original graph, dropping to about $37-38 \% \mathrm{O}_{2}$ for a dry concentrate $(0.1 \%$ moisture), demonstrating the strong impact of concentrate moisture in autogenous copper smelting.

Although no proven gas injection technology for matte smelting capable of enrichment levels of $48 \%$ and above in submerged tuyeres was available at the time (early 1980s), the need for such an injection technology was not even warranted. Operators of the new bath NR and TC smelting vessels were still learning the practice of using larger amounts of oxygen in smelting and the enrichment levels achieved, $30-32 \% \mathrm{O}_{2}$, were still far from the abovementioned upper limits of $37-38 \%$ and $48-50 \%$ for dry and wet concentrates, respectively. Nevertheless, fully autogenous operation was not even the goal as the supplemental use of coal or coke was seen in both Canada and Chile as beneficial to the process chemistry. At their apogee in the early 1990s, more than a dozen NRs and TCs were in operation and both Noranda and Codelco were promoting their matte smelting vessels as 'technologies of choice for emerging economies of

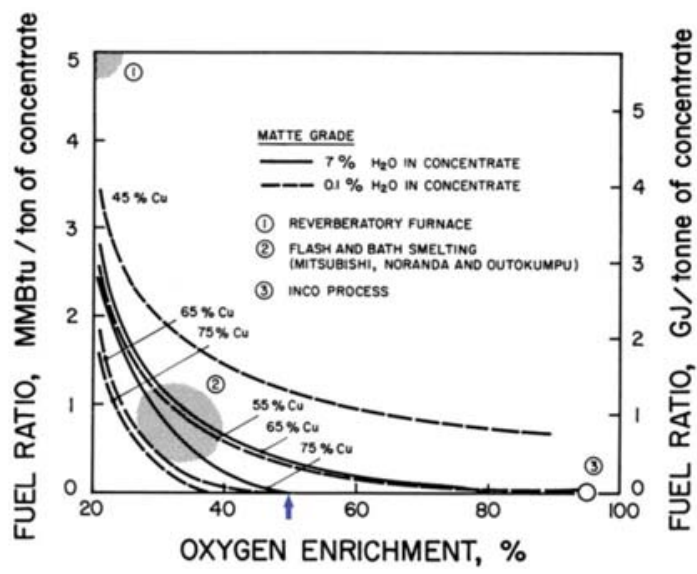

Figure 3-Effect of oxygen enrichment, concentrate moisture, and matte grade on the fossil fuel requirements per ton of chalcopyrite concentrate (reproduced from Mackey and Tarassoff, 1983) 


\section{Sonic injection in sulphide bath smelting: an update}

the 21st century' due to their low capital cost, flexibility in processing various feeds, and ease of retrofit into existing converter aisles.

Fast-forward to 2018 and only two NRs (the Horne and Altonorte smelters) and six TCs (Caletones, Chuquicamata, Hernan Videla Lira, La Caridad, Las Ventanas, and Potrerillos smelters) remain in commercial operation as the flash furnace has continued to rule supreme and the other bath smelting technologies, the top submerged lancing (TSL) furnaces (Isasmelt and Ausmelt) and the SKS/BBS furnace, gained momentum.

\section{The Queneau-Schuhmann-Lurgi reactor and bottom- blowing smelting furnace}

The original concept of the QS reactor for copper smelting was developed two years after the Savard-Lee concentric tuyere was commercially implemented in steelmaking. Queneau and Schuhmann were impressed with the concentric tuyere and believed its use in copper smelting would provide the smelting intensity they were envisioning while limiting the off-gas volumes (Queneau and Schuhmann, 1974). History will remember that the copper industry rejected their concept while a visionary from Europe, Werner Schwartz of Lurgi, saw its potential for the lead industry. The new reactor developed with Lurgi, hence the acronym QSL for QueneauSchuhmann-Lurgi, became the first bottom-blowing smelting reactor in the nonferrous industry. Kapusta and Lee (2013) provided details of the QSL process developments, from bench and pilot scale to demonstration and commercial plants.

The design of the concentric oxygen injector also evolved greatly during the development of the QSL process. Tested in a demonstration plant, the gear-type design, as opposed to the earlier simple pipe-in-a-pipe design, was adopted for commercial operation to reduce the gas momentum by dividing the gas streams into many small conduits, as illustrated on Figure 4. If the gas momentum was indeed lowered, the required pressure to achieve sonic velocity was drastically increased to the range 1200 to $1600 \mathrm{kPag}$ according to the research archives from Air Liquide and Lurgi. I will elaborate later in the paper on the reasons why such high pressures were needed.

By the early 1990s, four commercial QSL reactors had been designed, built, and commissioned at Cominco, Trail,
BC, Canada, in 1990 (120 000 t/a original design capacity, no longer in operation), Berzelius, Stolberg, Germany, in 1990 (80 000 t/a original design capacity, currently 155000 t/a), CNIEC, Baiyin, China, in 1990 (52 000 t/a original design capacity, no longer in operation), and Korea Zinc, Onsan, South Korea, in 1991 (60 000 t/a original design capacity, currently above $130000 \mathrm{t} / \mathrm{a})$.

The SKS/BBS furnace developed by the Chinese bears such a marked resemblance to the QSL vessel that eminent metallurgists in the western world questioned its chances of success in copper smelting, even dismissing its claim to be a new invention. Kapusta and Lee (2013) suggested instead that the SKS/BBS furnace was an adoption of the QSL concept with bottom-blowing shrouded injectors that was adapted to copper smelting, since only the oxidizing section of the QSL reactor was retained for the design of the SKS/BBS furnace. This, if not an invention in itself, is certainly a notable innovation as it took a copper smelting process concept - the $\mathrm{Cu}-\mathrm{QS}$ process as described by Queneau and Schuhmann (1974) - which was rejected by the global copper industry in its time, and developed it into one of the most important matte smelting technologies in China.

I have always assumed that the goal of the Chinese SKS/BBS innovators was to develop a high-intensity smelting process that could treat wet feed with ultra-high oxygen injection and produce low volumes of off-gases at higher $\mathrm{SO}_{2}$ strength. A study with my colleagues at BBA (Kapusta, Larouche, and Palumbo, 2015) showed that in spite of much disbelief from the western copper industry experts, this assumed goal was actually achieved: the SKS/BBS furnaces examined were more intense than the NR/TC reactors, even at lower feed grades of $22 \% \mathrm{Cu}$ (versus $37 \%$ for the NR and $27 \%$ for the TC in the study).

The SKS/BBS injector design, at least as presented in publications from China ENFI Engineering and Dongying Fangyuan, also has some strong resemblance to the QSL injectors based on the Savard-Lee tuyere, as illustrated in Figure 5. The key difference, however, is the reported low pressure of operation of the SKS/BBS injectors, at 400 to $600 \mathrm{kPag}$, apparently as a means to limit the energy cost of the process.

The question that comes to mind is why did the QSL inventors recommend the use of a very high pressure (up to $1600 \mathrm{kPag}$ ) if the much lower pressure (below $600 \mathrm{kPag}$ )

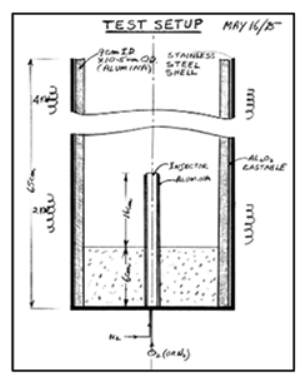

(a)

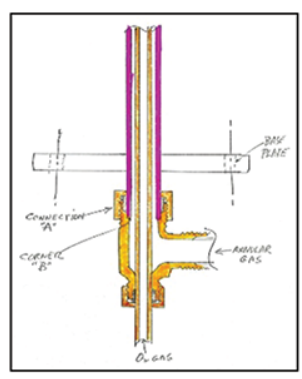

(b)

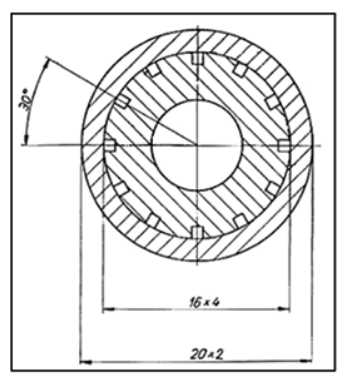

(c)

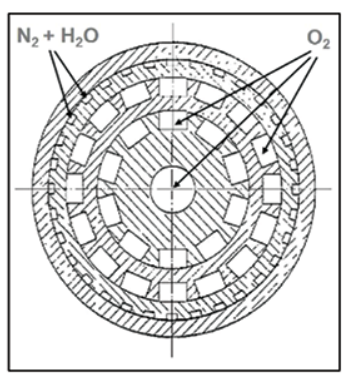

(d)

Figure 4-Evolution of the QSL oxygen injector: (a) bench scale, 1975; (b) pilot scale, 1977; (c) demonstration plant, 1981-86; and (d) commercial plant, 1989. (Air Liquide Canada Archives) 


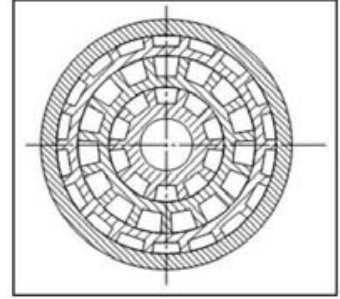

(a)

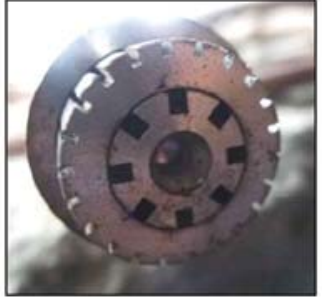

(b)

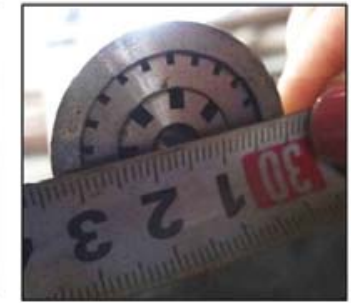

(c)

Figure 5-SKS/BBS shrouded injectors: (a) cross-section drawing from Hao et al. (2013); (b) and (c) photographs of SKS injector tip from a China ENFI Engineering presentation (2013)

used in China is sufficient? The true question is actually whether the gases flowing through a multitude of small orifices of a gear-type Savard-Lee shrouded injector could reach sonic velocity (jetting regime) with pressures in the range of 400 to $600 \mathrm{kPag}$ ? In the next section, I will briefly explain the principle of injection in jetting regime, attempting to dispel some of the myths about sonic injection, and will provide a bubbling-jetting map of inlet or back-pressure requirements for various orifice/tuyere diameters at two different submergences. This map should provide readers with a quick diagnosis tool to evaluate whether or not a process is operated in jetting regime, based on the single-pipe tuyere or shrouded injector design and the claimed operating pressure range.

\section{Sonic injection concepts - jetting regime}

Following the pioneering work of Savard and Lee, which triggered a transformation of the metallurgical landscape, much attention was devoted to the dynamics of submerged gas injection into molten metals. The wealth of knowledge on submerged gas injection phenomena produced in the 1970s and 1980s is well documented in the seminal paper of Brimacombe et al. (1990). I personally gained further theoretical knowledge and new practical experience from plant trials conducted by Air Liquide in the 1990s at Union Minière's Hoboken smelter in Belgium - now Umicore (Bustos, Cardoen, and Janssens, 1995) - and at Falconbridge's Sudbury smelter in Canada - now Glencore Nickel (Bustos et al., 1999). This newly acquired know-how allowed me to successfully contribute to the subsequent commercial implementation of shrouded injection in the Slag Make Converter (SMC) at the Falconbridge smelter (Bustos and Kapusta, 2000; Kapusta, Stickling, and Tai, 2005) and in the Hoboken converters at the Thai Copper Industries smelter in Thailand (Kapusta, Wachgama, and Pagador, 2007; Pagador et al., 2009). More recently, I acquired some additional insights with BBA during plant trials of singlepipe sonic tuyeres in a Peirce-Smith converter at the Lonmin Platinum smelter in South Africa (Kapusta et al., 2012). Based on this acquired theoretical knowledge and practical experience, I offer in my short course on gas injection phenomena the following main characteristics and advantages of sonic injection.

> Achieving sonic velocity (jetting regime) requires higher pressures than conventional bubbling regime, typically above $250 \mathrm{kPag}$ depending on tuyere diameter and submergence.
> The injected gases discharge as a continuous jet in the molten bath - hence the term jetting regime characterized by a swarm of smaller bubbles.

> Sonic tuyeres or injectors do not require punching (no tuyere blockage) as the bath does not come in contact with or penetrate the sonic tuyeres or injectors, and therefore gas leaks and losses at the back of the tuyeres are greatly reduced or eliminated.

> Properly designed and operated sonic tuyeres and injectors reduce slopping and splashing.

> Sonic injection is characterized by a stable gas flow rate throughout the blowing period, and therefore a controlled amount of oxygen is delivered to the bath, which translates into better metallurgical control.

> Sonic injection also allows higher levels of oxygen enrichment, typically in the range of $25-45 \%$ with single-pipe sonic tuyeres, and above $35 \%$ with sonic shrouded injectors.

In addition to punchless operation and stable gas flow rate, sonic injection under jetting regime is also characterized by higher vessel intensity due to higher permissible oxygen enrichment levels. This higher oxygen intensity allows a higher reverts and cold charge reprocessing rate while generating lower off-gas volumes, which therefore reduces the propensity for fugitive emissions.

\section{Dispelling myths}

Adoption and implementation of sonic injection in base metals occurred much later and at a much slower pace than in the steel industry, partly due to some misconceptions and misunderstandings of the technology, and also due to the slower pace of process intensification and tonnage oxygen usage in nonferrous metallurgy compared with steelmaking. One of the biggest myths about sonic injection within the base metals industry is that 'very high pressures' are required and that the benefits of operating in jetting regime are cancelled out by the cost of delivering the gases at these perceived 'very high pressures'. Jetting regime certainly does require higher pressures than conventional bubbling regime, but let us evaluate this myth quantitatively before we dispel it. Another myth is that bottom-blowing is 'obviously' better than side-blowing as it provides a longer residence time for the injected gases, and therefore results in better oxygen efficiency. I will also evaluate and challenge this belief.

Sonic flow mapping with bubbling to jetting transition The basic principle in sonic injection is to consider the gases 


\section{Sonic injection in sulphide bath smelting: an update}

flowing through a tuyere or injector to be compressible and adiabatic with wall friction effects through ducts of constant cross-sectional area (inner pipe and annulus for a shrouded injector). This type of flow is commonly known as Fanno flow. From the compressible fluid flow literature (for example Oosthuizen and Carscallen, 1997; Saad, 1985), deriving the Fanno flow equations and integrating over the length of the tuyere or injector while setting the value of the Mach number at the tip to unity $\left(M_{\text {outlet }}=1\right)$ - since the fundamental design criteria of a sonic tuyere or injector is that both gas streams are to exit at sonic velocity - the following expressions for Fanno flow are obtained:

$$
\begin{aligned}
& \frac{4 f L}{D_{h}}=\frac{1-M_{\text {inlet }}^{2}}{k M_{\text {inlet }}^{2}}+\frac{k+1}{2 k} \operatorname{Ln}\left[\frac{(k+1) M_{\text {inlet }}^{2}}{2\left(1+\frac{k-1}{2} M_{\text {inlet }}^{2}\right)}\right] \\
& \frac{P_{\text {inlet }}}{P_{\text {outlet }}}=\frac{1}{M_{\text {inlet }}} \sqrt{\frac{\frac{k+1}{2}}{1+\frac{k+1}{2} M_{\text {inlet }}^{2}}}
\end{aligned}
$$

where $f, L$, and $D_{h}$ are the friction factor, the length, and the hydraulic diameter of the duct, respectively, $k$ is the $\mathrm{C}_{\mathrm{p}} / \mathrm{C}_{\mathrm{V}}$ ratio of the gas, $M_{\text {inlet }}$ is the Mach number at the inlet of the duct, and $P_{\text {inlet }}$ and $P_{\text {outlet }}$ are the inlet and outlet pressures of the gas stream.

Based on my experience, sonic flow conditions (Mach 1) are indeed necessary but not necessarily sufficient for maintaining stable jetting. The necessary and sufficient condition for sonic tuyere and injector design, whether for matte smelting, converting, or refining, is that the fully expanded Mach number, $M_{\text {exp }}$, attains a critical value larger than unity. This critical value is determined by applying the Prandtl-Meyer theory of expansion wave to sonic gas flow, as suggested by Ozawa and Mori (1983a, 1983b), who speculated that an underexpanded gas jet attaining sonic flow at the tuyere exit would discharge as a supersonic jet into molten metal in the immediate vicinity of the tuyere. They derived the formulation to characterize the initial expansion angle and the fully expanded Mach number of the supersonic jet as follows:

$$
\begin{aligned}
& \theta_{c}=2 \sqrt{\frac{k+1}{k-1}} \tan ^{-1}\left(\sqrt{\frac{k-1}{k+1}\left(M_{\text {exp }}^{2}-1\right)}\right)-\tan ^{-1}\left(\sqrt{M_{\text {exp }}^{2}-1}\right) \\
& M_{\text {exp }}=\sqrt{\left[\left(\frac{P_{\text {exit }}}{P_{\text {metal }}}\right)^{(k-1) / k}\left(\frac{k+1}{2}\right)-1\right] \frac{2}{k-1}}
\end{aligned}
$$

where $\theta_{c}$ is the initial expansion angle (or jet cone angle), $M_{\text {exp }}$ is the fully expanded Mach number of the supersonic jet, $P_{\text {exit }}$ is the gas pressure at the tuyere exit and $P_{\text {metal }}$ is the metallostatic pressure of the bath above the tuyere exit. Figure 6 provides a graphical representation of the initial expansion angle to help understand its significance. In their research work, Oryall and Brimacombe (1976) determined that the initial expansion angle for submerged gas injection under bubbling regime is in the range $150^{\circ}$ to $155^{\circ}$ (bubble growth prior to detachment). Farmer et al. (1989) conducted a study with small tuyeres with diameters in the range 1.4 to $2.0 \mathrm{~mm}$. Based on their results, they proposed the criterion that stable jetting regime is attained at a value of $M_{\text {exp }}$ above 1.25 , corresponding to an initial expansion angle larger than $10^{\circ}$. Although providing an interesting comparison between bubbling and jetting in terms of initial expansion angle, the applicability of their criterion is, however, limited to the range of tuyere diameters they used in their study (1.4 to $2.0 \mathrm{~mm}$ ). A complete review of the Prandtl-Meyer theory and re-derivation of the mathematical expressions was recently published by Kapusta (2017).

Although $M_{\text {exp }}$ is mathematically independent of the tuyere or injector diameter or the liquid-to-gas density ratio, based on my experience in sonic injection in both copper and nickel converting, the minimum or critical value of $M_{\text {exp }}$, and correspondingly $\theta_{\mathcal{C}}$, required for stable jetting is impacted by the physical characteristics of the gas-molten bath system, particularly the gas flow rate and momentum, and therefore indirectly to the tuyere or injector diameter.

Let us now revisit the myth that 'very high pressures' are needed to achieve sonic flow or jetting regime by exploring the pressure and flow rate requirements for jetting as a function of tuyere or injector diameter and submergence. For illustration purposes, I have performed a series of calculations using Equations [1] to [4] to determine the minimum tuyere back-pressure required to achieve sonic flow as a function of tuyere diameter for a tuyere submergence of $0.75 \mathrm{~m}$ and $1.10 \mathrm{~m}$, with a bath density above the tuyere of $4500 \mathrm{~kg} / \mathrm{m}^{3}$ and $4700 \mathrm{~kg} / \mathrm{m}^{3}$, respectively. The portion of bath above the tuyere being a mixture of white metal and slag, I simply assumed a higher density at the $1.10 \mathrm{~m}$ submergence to account for a larger proportion of white metal than slag at a higher bath depth. Finally, I considered a $1.00 \mathrm{~m}$ long tuyere in all calculations. The results are depicted in the graph in Figure 7, which corresponds to what I call a 'sonic flow mapping' for the specific conditions of the case study.

The curves for the two submergence cases correspond to the boundaries for the transition between the end of the bubbling regime at a Mach number close to but lower than

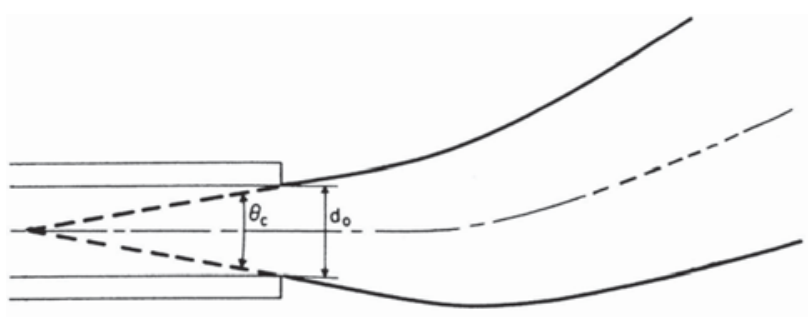

Figure 6-Schematic representation of the initial expansion angle $\theta \mathrm{c}$ of a gas jet envelope for submerged injection into molten metals and mattes (adapted from Themelis, Tarassoff, and Szekely, 1969) 


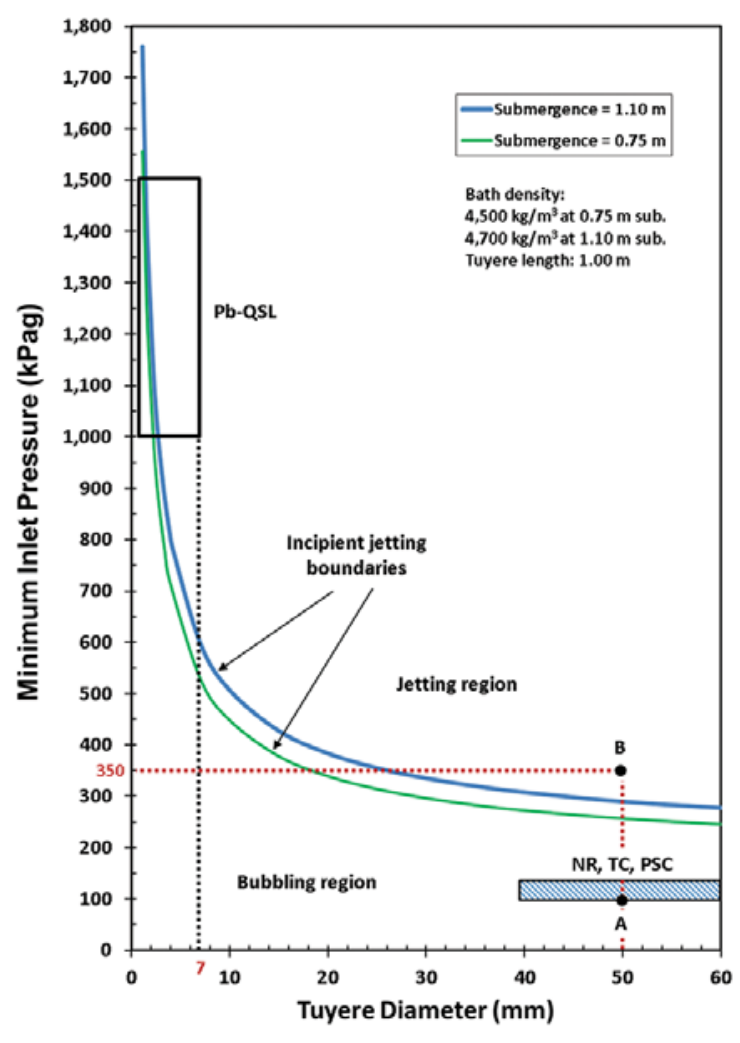

Figure 7-Sonic flow mapping: plots of the minimum tuyere backpressure requirement, as a function of tuyere diameter and submergence, to achieve incipient jetting (Mach 1) for a $1 \mathrm{~m}$ long single-pipe tuyere

unity and the beginning of the stable jetting regime at a fully expanded Mach number, also close to but greater than unity. These curves, obtained by calculating the minimum tuyere back-pressure required to achieve sonic flow as a function of tuyere diameter, actually represent the incipient jetting boundaries.

The areas of the graph below and above the boundaries correspond to the bubbling and jetting regions, respectively. For example, a $50 \mathrm{~mm}$ inner diameter single-pipe tuyere injecting compressed air and oxygen at a back-pressure of $100 \mathrm{kPag}$ is operating in the bubbling regime - point A in the bubbling region of the graph. If the injection back-pressure is raised above $300 \mathrm{kPag}$ (above the incipient jetting curves for the two submergence cases at an inner diameter of $50 \mathrm{~mm}$, to $350 \mathrm{kPag}$ for instance - Point B in the jetting region of the graph) the tuyere will operate in the jetting regime. Arthur, Siegmund, and Schmidt (1992) indicated that a QSL reactor for lead sulphide smelting needed to operate within the tuyere back-pressure range of 1000 to $1500 \mathrm{kPag}$ using a Savard-Lee-type concentric tuyere with a structure as shown on Figure 8, while Ashman (1998) indicated back-pressures as high as $1900 \mathrm{kPag}$. Such high gas pressures are necessary due to the very small flow areas of the $1.0 \mathrm{~mm}$ by $1.6 \mathrm{~mm}$ orifices (1.43 mm equivalent diameter) for the shrouding gas mixture of nitrogen, atomized water, and a hydrocarbon gas, and the $3.0 \mathrm{~mm}$ by $4.5 \mathrm{~mm}$ orifices (4.15 mm equivalent diameter) for the reactive oxygenenriched air. The box in the top left corner of the graph represents the QSL reactor injection back-pressure range from Arthur, Siegmund, and Schmidt (1992). The textured box in the bottom right corner corresponds to the operating range of conventional low-pressure injection of the NR, TC, and Peirce-Smith converter (PSC) with tuyere diameters between 40 and $60 \mathrm{~mm}$ and back-pressures of about 100 to $140 \mathrm{kPag}$

\section{Side blowing versus bottom blowing}

I recently published a study of submerged gas jet penetration into molten metal and compared the bubbling versus jetting regime and side versus bottom blowing (Kapusta, 2017). For this study, I used the mathematical formulation of a gas jet trajectory and penetration into a liquid that was developed almost 50 years ago by Themelis, Tarassoff, and Szekely (1969). Their formulation was based on continuity and momentum balances to calculate an idealized gas jet axis trajectory based on parameters such as tuyere diameter and inclination angle, jet cone angle or initial expansion angle, modified Froude number, and bath and gas densities. Figure 9 represents a scaled diagram of a smelting vessel with a 4.0 m internal diameter, a $1.0 \mathrm{~m}$ height of white metal, and an average slag height of $1.70 \mathrm{~m}$.

The diagram offers a comparison of the gas jet trajectories for a side-blowing tuyere positioned at a $49^{\circ}$ angle from the vertical and inclined downward from the horizontal by $18^{\circ}$ and a bottom-blowing tuyere positioned at a $22^{\circ}$ angle from the vertical and installed radially. The trajectory curves on Figure 9 represent the calculated 'idealized' gas jet axis trajectories using an initial expansion angle value of $20^{\circ}$ (Kapusta, 2017). The actual gas jet boundaries widen as the gas penetrates into the bath and away from the tuyere tip. The width of the gas jet depends on a number of parameters, including the initial expansion angle, the gas and bath densities, as well as the tuyere orifice diameter, inclination angle, and submergence.

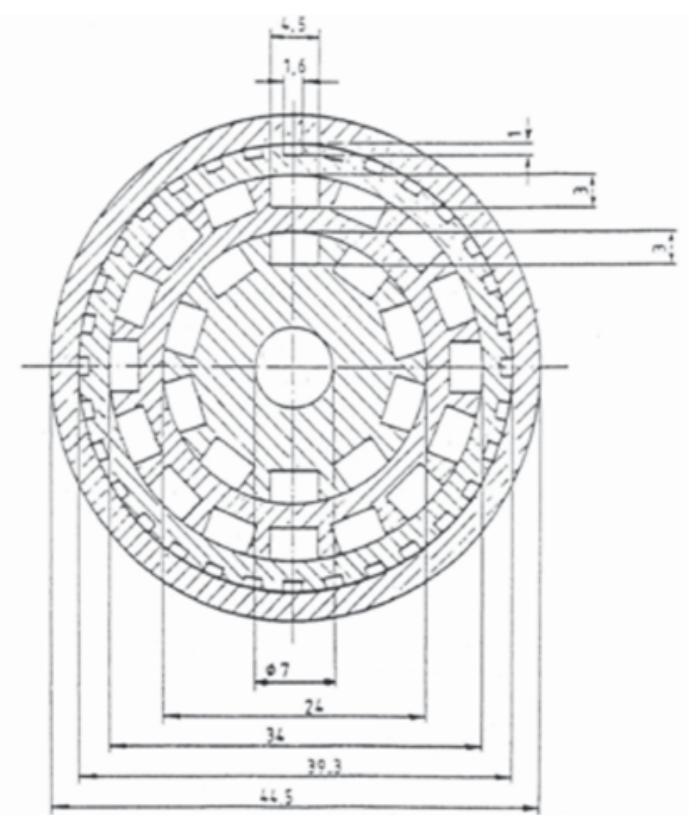

Figure 8-Cross-section of a QSL oxidation S-injector (reproduced from Arthur, Siegmund, and Schmidt, 1992) 


\section{Sonic injection in sulphide bath smelting: an update}

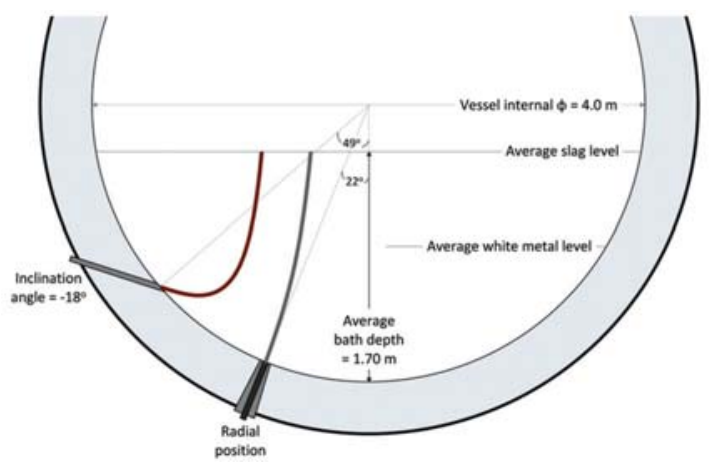

Figure 9-Scaled drawing of a copper bath smelting vessel with visualization of the calculated gas jet axis trajectories under jetting regime for side and bottom blowing with an initial expansion angle of $20^{\circ}$ and a tuyere length of $1.0 \mathrm{~m}$ (Kapusta, 2017)

One surprising result was that the calculated length of the trajectories for side and bottom blowing under the conditions used in Figure 9 were about the same, at 156 and $159 \mathrm{~cm}$ for side and bottom blowing, respectively. This result seems to indicate that bottom blowing does not necessarily provide a longer gas jet trajectory than side blowing with an optimum tuyere inclination angle; in fact, the residence time for the reactive gas to create conditions for oxygen efficiencies is very similar. In practice, however, the more significant difference, in my opinion, resides in the matte and slag recirculation flow patterns generated by side blowing compared with bottom blowing. The key for success for both side and bottom blowing in jetting regime is that the injectors must be designed and operated to maintain sonic flow while ensuring the degree of underexpansion is sufficient, yet not too large, so that the gas jet exiting at sonic velocity at the tip of the tuyere becomes supersonic immediately after exiting the tuyere (Prandtl-Meyer flow).

\section{Conclusions}

The nonferrous metals industry has been reluctant to implement sonic injection and is still very slow in deploying it commercially in spite of its great advantages. I believe that there are three main reasons for this slow adoption and implementation. The first is the aversion to risk and change that characterizes the copper industry, in great contrast to the steel industry. The second is more historical than technological. One has to remember that the Savard-Lee concentric tuyere was invented for the steel industry at a time, in the 1960s and 1970s, when capturing and treating process off-gases in copper and nickel processing was not legislated and when 'superstacks' spewing and dispersing $\mathrm{SO}_{2}$-laden fumes were the pride of the smelters and towns where they were standing tall. Acid plants were still uncommon and a distant staple of a copper or nickel smelter. With no legislation to 'encourage' mining companies to reduce their $\mathrm{SO}_{2}$ and dust emissions, the cost of implementing sonic injection with compressors rather than blowers was too high, with no means to amortize the investment. The third reason has a human dimension and is related to the reluctance of smelter managers, engineers, and operators to believe that sonic injection was, and is, punchless. Peirce-Smith converters, for example, have operated for more than a hundred years with punching of the tuyeres, first manually, then mechanically, with a dedicated crew of operators or automatically in the best cases.

The nonferrous industry has certainly matured as the use of tonnage oxygen has become a prevalent reality to boost process intensity. Legislation to protect the environment and populations around smelters has also matured and some mining companies have transformed the obligation to comply with new environmental and work hygiene legislation into opportunities to improve the competitiveness of their operations. Their corporate social responsibility - combined with a spirit of technological innovation - has allowed their smelters to sit comfortably in the lower quartile of the cash cost curve of worldwide smelters. Some of these lower cost smelters have made high- or ultra-high-oxygen injection an essential part of their technological development plan, leading them to adopt and implement variations of the Savard-Lee concentric tuyere.

I am convinced that the nonferrous industry has finally seen the dawn of sonic injection with its growing adoption in China and that sonic injection in bath smelting, converting, and refining will become a mainstream technology within the next ten years. The wealth of knowledge in submerged gas injection phenomena and the practical and operational experience acquired by the few companies that have operated high-intensity reactors equipped with sonic tuyeres or injectors will be put to use to further improve the design and lifespan of sonic tuyeres and injectors. Examples of companies with experience in high-intensity sonic injection include Berzelius in Germany and Korea Zinc in South Korea with their QSL reactors for lead processing, Glencore Nickel in Canada with their original Slag Make Converter (now replaced by two hybrid vessels capable of both converting and slag cleaning using high-oxygen-shrouded injectors), and numerous lead and copper smelters in China using SKS/BBS furnaces.

Back in 1998 during his short course on Peirce-Smith converting at the TMS Annual Meeting, Tony Eltringham told Alejandro Bustos - my mentor at the time at Air Liquide Canada - that 'Air Liquide was 20 years ahead of the industry with its Air Liquide Shrouded Injection (ALSI) Technology'. Twenty years later and no longer a junior in the field, I am delighted to be witnessing the current evolution of the copper and nickel industry with its renewed interest in high-oxygen sonic injection, an evolution that is fully in sync with my work findings and with Tony Eltringham's foresight. I truly look forward to taking part in this new transformation of the metallurgical landscape of the nonferrous industry and to contributing in any way I can in the deployment and optimization of sonic injection.

\section{Acknowledgements}

I wish to acknowledge and thank the management of BBA for encouraging me and giving me the opportunity to spend time to prepare this manuscript and allowing me to present it at Cu-Co 2018 in Zambia and to publish it in the SAIMM Journal. Without sharing, knowledge and experience get lost and so does the chance for individuals to help our industry move forward another step. 


\section{Sonic injection in sulphide bath smelting: an update}

\section{References}

ArthuR, P., Siegmund, A., and Schmidt, M. 1992. Operating experience with QSL submerged bath smelting for production of lead bullion. Proceedings of the SavardLee International Symposium on Bath Smelting. Brimacombe, J.K., Mackey, P.J., Kor, G.J.W., Bickert, C., and Ranade, M.G. (eds). The Minerals, Metals and Materials Society of AIME, Warrendale, PA. pp. 127-145.

Ashman, D. 1998. Lead pyrometallurgy. Lead and zinc processing short course at the 1998 Conference of Metallurgists, Calgary, Alberta, 15-16 August 1998. The Metallurgical Society of CIM, Montreal, QC.

Brimacombe, J.K., Nakanishi, K., Anagbo, P.E., and Richards, G.G. 1990. Process dynamics: gas-liquid. Proceedings of the Elliott Symposium on Chemical Process Metallurgy. Koros, P.J. and St. Pierre, G.R. (eds). The Iron and Steel Society of AIME (ISS), Warrendale, PA. pp. 343-412.

Bustos, A.A., Cardoen, M., and Janssens, B. 1995. High oxygen enrichment at UM-Hoboken converters. Proceedings of Copper 95 - Cobre 95, Vol. IVPyrometallurgy of Copper. Chen, W.J., Diaz, C., Luraschi, A., and Mackey, P.J. (eds). The Metallurgical Society of CIM, Montreal, QC. pp. 255-269.

Bustos, A.A., Kapusta, J.P., Macnamara, B.R., and Cofrin, M.R. 1999. High oxygen shrouded injection at Falconbridge. Proceedings of Copper 99 Cobre 99 International Conference, Vol. VI-Smelting, Technology Development, Process Modeling and Fundamentals. Diaz, C., Landolt, C., and Utigard, T. (eds). The Minerals, Metals and Materials Society of AIME, Warrendale, PA. pp. 93-107.

Bustos, A.A. and KAPUSTA, J.P. 2000. High oxygen shrouded injection in copper and nickel converters. Proceedings of the Brimacombe Memorial Symposium. Irons, G.A. and Cramb, A.W. (eds). The Metallurgical Society of CIM, Montreal, QC. pp. 107-124.

China ENFI EngineERing CoRPoration. 2013. Oxygen bottom blowing copper smelting technology (SKS). http://wenku.baidu.com/view/ 4a6be5990029bd64783e2cf1.html [accessed 11 March 2018].

FARMER, L., LACH, D., LANYI, M., and Winchester, D. 1989. Gas injection tuyere design and experience. Proceedings of the 72nd Steelmaking Conference. The Iron and Steel Society of AIME (ISS), Warrendale, PA. pp. 487-495.

Hao, X., Lu, Z., Wei, K., Zhang, Z., Hu, L., Li, B., Wen, Z., Su, F., and Yu, Y. 2013. Development and application of oxygen bottom-blowing $\mathrm{Cu}$ smelting technology. Proceedings of the Copper 2013 International Copper Conference, Vol. III (Book 2)-The Nickolas Themelis Symposium on Pyrometallurgy and Process Engineering. Bassa, R., Parra, R., Luraschi, A., and Demetrio, S. (eds). Instituto de Ingenieros de Minas de Chile, Santiago. pp. 451-459.

Hoefele, E.O. and Brimacombe, J.K. 1979. Flow regimes in submerged gas injection. Metallurgical Transactions B, vol. 10B, no. 4. pp. 631-648.

International Copper Study Group. 2017. The World Copper Factbook 2017. Lisbon.

KAPUSTA, J.P. 2004. JOM World Nonferrous Smelters Survey, Part I: Copper. JOM, July. pp. 21-27

KAPUSTA, J.P. 2013. Sonic injection in bath smelting and converting: myths, facts and dreams. Proceedings of the Ralph Harris Memorial Symposium. Harris, C., Kashani-Nejad, S., and Kreuh, M. (eds). The Metallurgical Society of CIM, Montreal, QC. pp. 267-317.

KAPUSTA, J.P. 2017. Submerged gas jet penetration: a study of bubbling versus jetting and side versus bottom blowing in copper bath smelting. JOM, June. pp. 970-979.

Kapusta, J.P.T., Davis, J., Bezuidenhout, G.A., Lefume, S., and ChibwE, D.K. 2012. Industrial evaluation of sonic injection in a Peirce-Smith converter at the Lonmin Platinum Smelter. Proceedings of the 51st Conference of Metallurgists - Towards Clean Metallurgical Processing for Profit, Social and Environmental Stewardship Symposium. Schonewille, R.H., Rioux, D., Kashani-Nejad, S., Kreuh, M., and Muinonen, M.E.S. (eds). The Metallurgical Society of CIM, Montreal, QC. pp. 43-58.

KaPusta, J.P.T., LARouche, F., and Palumbo, E. 2015. Adoption of high oxygen bottom blowing in copper matte smelting: why is it taking so long?
Proceedings of the Torstein Utigard Memorial Symposium. Muinonen, M., Marin, T., and Stubina, N. (eds). The Materials and Metallurgical Society of CIM, Montreal, QC, Canada. Paper no. 9078.

KAPUSTA, J.P.T. And LeE, R.G.H. 2013. The Savard-Lee shrouded injector: a review of its adoption and adaptation from ferrous to non-ferrous pyrometallurgy. Proceedings of the Copper 2013 International Conference, Volume III (Book 2) - The Nickolas Themelis Symposium on Pyrometallurgy and Process Engineering. Bassa, R., Parra, R., Luraschi, A., and Demetrio, S. (eds). Instituto de Ingenieros de Minas de Chile, Santiago. pp. 523-558.

KAPUSTA, J. and RichARDS, G. 2009. Injection phenomena in the PS converter the teachings of J. Keith Brimacombe and his UBC research team. International Peirce-Smith Converting Centennial Symposium Short Course. 138th Annual Meeting \& Exhibition of TMS, San Francisco.

KAPUSTA, J.P., STICKLING, H., and TAI, W. 2005. High oxygen shrouded injection at Falconbridge: five years of operation. Proceedings of Converter and Fire Refining Practices. Ross, A., Warner, T., and Scholey, K. (eds). The Minerals, Metals and Materials Society of AIME, Warrendale, PA. pp. 47-60.

Kapusta, J.P.T., Wachgama, N., and Pagador, R.U. 2007. Implementation of the Air Liquide shrouded injector (ALSI) technology at the Thai Copper Industries smelter. Proceedings of the Copper 2007 - Cobre 2007 International Conference, Vol. III (Book 1) - The Carlos Diaz Symposium on Pyrometallurgy. Warner, A.E.M., Newman, C.J., Vahed, A., George, D.B., Mackey, P.J., and Warczok, A. (eds). The Metallurgical Society of CIM, Montreal, QC. pp. 483-500.

MAcKey, P.J. and BRIMACOMBE, J.K. 1992. Savard and Lee - transforming the metallurgical landscape. Proceedings of the Savard/Lee International Symposium on Bath Smelting. Brimacombe, J.K., Mackey, P.J., Kor, G.J.W., Bickert, C., and Ranade, M.G. (eds). The Minerals, Metals and Materials Society of AIME, Warrendale, PA. pp. 3-28.

MACKEY, P.J. and TARASSOFF, P. 1983. New and emerging technologies in sulphide smelting. Proceedings of Advances in Sulfide Smelting Symposium, Vol. 2. Technology and Practice. Sohn, H.Y., George, D.B. and Zunkel, A.D. (eds). The Metallurgical Society of AIME, New York, NY. pp. 399-426.

Oosthuizen, P.H. and CARSCALlen, W.E. 1997. Compressible Fluid Flow. McGraw-Hill, New York.

Oryall, G.N. and Brimacombe, J.K. 1976. The physical behavior of a gas jet injected horizontally into liquid metal. Metallurgical Transactions $B$, vol. 7B, no. 3. pp. 391-403.

OzAwA, Y. and MoRi, K. 1983a. Behavior of gas jets injected into a twodimensional liquid metal bath. Transactions of the ISIJ, vol. 23. pp. 759-763.

OZAWA, Y. and MoRI, K. 1983b. Characteristics of jetting observed in gas injection into liquid. Transactions of the ISIJ, vol. 23. pp. 764-768.

Pagador, R., Wachgama, N., Khuankla, C., and Kapusta, J.P. 2009. Operation of the Air Liquide shrouded injector (ALSI) technology in a Hoboken siphon converter. Proceedings of the International Peirce-Smith Converting Centennial Symposium. Kapusta, J.P.T. and Warner, A.E.M. (eds). The Minerals, Metals and Materials Society of AIME, Warrendale, PA. pp. 367-381.

Queneau, P.E. 1977. Oxygen technology and conservation. Metallurgical Transactions B, vol. 8B, September. pp. 357-369.

QuENEAU, P.E. and SchuHMAnN, R. 1974. The Q-S oxygen process. Journal of Metals, August. pp. 2-4.

SAAD, M.A. 1985. Compressible Fluid Flow. Prentice-Hall., Englewood Cliffs, NJ.

SAVARD, G. and LEE, R. 1966. Air Liquide. Improvements in metallurgical process. French patent 1450718.

Themelis, N.J., TARAssoff, P., and Szekely, J. 1969. Gas-liquid momentum transfer in a copper converter. Transactions of the Metallurgical Society of AIME, vol. 245. pp. 2425-2433. 